\title{
Application of GIS and Remote Sensing in Determining Trends in Wind Energy Potential and Its Uses for Designing Development Strategies in Ghana
}

\author{
Nurideen Abdulai ${ }^{1}$, Leslie Mantei Donkor², Dennis Wiredu Asare ${ }^{3}$ \\ ${ }^{1}$ Department of Energy and Environmental Engineering, University of Energy and Natural Resources (UENR), \\ Sunyani, PhD Candidate in Sustainable Energy Management. \\ ${ }^{2}$ Department of Energy and Environmental Engineering, University of Energy and Natural Resources (UENR), \\ Sunyani, Member of IEE, AEE and Lecturer at Accra Institute of Technology (AIT). \\ ${ }^{3}$ Department of Energy and Environmental Engineering, University of Energy and Natural Resources (UENR), \\ Sunyani, Member of IEE, AEE and Renewable Energy Engineer
}

Correspondence to: kinnurus@gmail.com

\begin{abstract}
This paper is purported to determine the wind energy potential of Ghana for 2010 and 2018 using GIS and RS technologies and how the result could be used to develop a country strategy that benefits the ordinary Ghanaian. In doing this, two different wind potential maps of Ghana were generated for 2010 and 2018 using data from Ghana meteorological Unit and Windfinder respectively. Moreover, the Inverse Distance Weighted interpolation of winds peed was used to generate the maps at different hub heights for 2010 and 2018. The results indicate that, the 2010 wind map showed wind speed is highest $(8 \mathrm{~m} / \mathrm{s})$ in the southernmost part of Ghana (i.e. Coastal part of Greater Accra and Volta Regions) at 10m high while the wind map of 2018 showed that wind speed is highest $(9 \mathrm{~m} / \mathrm{s})$ in the Upper East Region of Ghana at $10 \mathrm{~m}$ high. As wind energy is untapped in Ghana, we advised that Government should further explore the results for the Upper East Region in ascertaining that it was not influenced by Trade winds and apply to different sectors of the economy through appropriate institutional regulations. The wind energy in Northern Ghana should be dedicated to mechanized agriculture, augmenting electricity tariffs for the poor in those areas and extending electricity to rural communities that do not have access to the national grid under the rural electrification project. Meanwhile, the wind energy generated from the southern part of Ghana should be dedicated mostly to commercial and industrial activities.
\end{abstract}

Keywords: Wind Energy Potential, mechanized agriculture, industrial application, GIS, RS

\section{INTRODUCTION}

There is an increasing need and demand for Energy from Renewable Sources [1], [2][3], [4][5][6][7], to the extent that International organizations like the UN have spearheaded policies in building up strategies to facilitate the transition from fossil-fuel powered plants to Renewable Energy Sources. Two major issues inform this move - (1) depletion, price volatility and geopolitics of fossil fuel resources worldwide and (2) the massive increase in carbon dioxide emission emanating from fossil fuel consumption that contribute 
largely to global warming and climate change [6][4][7]-[9]. Despite the fact that several incentives have been put in place for all Clean Renewable Energy Sources, wind energy is the fastest growing Renewable Energy (RE) source in recent times with improved technologies and strategies to mitigate its environmental impact [10][11]. For instance, the World's Wind Energy Association reported the total installed wind capacity to reach a record high of 539GW at year-end 2017, up from 296GW in 2014. China leads this drive with $40 \%$ share of installed wind capacity as at 2017 [12]. This improvement has led to tremendous technological advancement in determining the wind power potential over the years. In this research work, we use GIS and Remote Sensing technologies to determine the wind energy potential of Ghana for the period 2010 and 2018 and how this benefits the country's energy sector.

The GIS and RS technology have been useful in all aspect of human life as it is suitable for wind energy potential mapping and wind power density determination [11][13][14][6]. The technology has been extensively used in this regard and has come out with significant reliable results useful in World energy research analysis. Much research work have taken place already on Ghana's wind energy potential by the Ministry of Energy and Energy Commission in the coastal regions [15][16][17]. This work particularly looks at the wind energy potential map of Ghana for 2010 and 2018 on change detection and its benefits to Ghana's energy sector.

The rest of the work is organized as follows: section two deals with the materials and methods, section three deals with data analysis and results while section four focuses on discussions and section five the conclusion.

\section{Literature Review}

GIS and RS have been applied in almost all aspects of human life and activities for change detection, and in aiding information and operations in Agriculture, Health, for Energy, disaster management and to detect early warning signs and impact of epidemic, as well as for enhancing productivity [9][9], [18]-[20]. The technology has been applied in the energy sector in recent times by several researchers [9], [11], [13], [21]-[24] applied GIS and RS to determine wind sites and potential through wind power density as well as the suitability of wind turbine sites and environmental factors in particular regions and countries.

Moreover, researchers like [6], [25], [26] have confirmed the suitability of GIS and RS in determining wind energy potentials and environmental factors for appropriate site locations. [18] also applied the GIS and RS technology for change detection and disease control. The Ministry of Energy in Ghana have mounted masks at 22 potential wind energy resource locations in Ghana at different heights in this regard [27]. The extant literature suggest that the wind energy potential of Ghana ranges from 200MW to 300MW [27][16]. With this RE potential in wind Essandoh et. al., conclude that wind energy resource is comparatively the best option for development by the Government of Ghana in trying to meet the $10 \%$ renewable obligation in Ghana's energy mix. Compared with solar and hydro [16], [28]-[31], wind energy is the least attended to in Ghana even though with promising prospects for electricity supply in the country and a lower levelized cost of electricity when life-cycle analysis is carried out [10][2]. This is partly because of lack technology and commitment. However, in all these situations, less attention has been paid to the use of GIS and RS to determine the wind energy potential in the country as well as detecting changes that might have occurred over the years rather than relying on unreliable data for decision-making. This work covers this research gap by 
employing a GIS-RS methodology or approach to determine the wind energy potential in Ghana for the years 2010 and 2018 and whether there is any potential for change.

\section{MATERIALS AND METHODS}

This section explains the methods used in arriving at our results for this work. The research in this paper relies on using Geoinformation (GIS) and Remote Sensing (RS) systems where maps showing different variables are overlapped to calculate and show impacts of different variables to wind energy potentials of various locations. GIS methods are also generally recommended by the European Commission in their guidance document for "Wind Energy Developments and Natura 2000".

\section{Data Sources}

Measured wind data were obtained from Ghana Meteorological Department for the year 2010. However, data for 2018 were obtained from wind finder (https://www.windfinder.com/) for Ghana.

\section{Methods of Measurement}

The wind power at a site can be obtained by a measurement device mounted on a pole at the height of the future wind generator. Collecting data for a whole year is not generally viable, so a couple of months of data can be taken and compared with data from a local weather station and then extrapolated for the year. Devices include: an anemometer - giving average daily wind speed, a wind totalizer - giving instantaneous wind speed and total wind over an extended period. Wind potential measurements were taken at height of $10 \mathrm{~m}$ for 10 different locations across Ghana.

\section{Wind speed variation with height}

The measured wind data were based on the $10 \mathrm{~m}$ height. However, the wind speeds at different heights can be interpolated to assess the availability of wind resources. Vertical wind speed profile for each station was interpolated by the power law equation [32]:

$$
v=v_{o}\left(\frac{Z}{z_{o}}\right)^{\alpha}
$$

Where $\mathrm{v}$ is wind speed estimated at desired height, $\mathrm{z} ; \mathrm{v}_{0}$ is wind speed measured at the reference height, $\mathrm{z}_{0} ; \alpha$ is the ground surface friction coefficient and calculated by the Counihan equation [33]. In this study, the vertical wind speed was interpolated at $10 \mathrm{~m}$ of hub heights.

\section{Inverse distance weighted (IDW) interpolation of wind speed}

In this study, World Geodetic System projection was used to project the map of Ghana based on Geographic Information System. Further, IDW method was used to calculate the unknown wind speed values for the surrounding [34][35]. The expression of IDW: 


$$
z_{u}=\frac{\sum_{i=1}^{S} z_{i} d_{i u}^{-k}}{\sum_{i=1}^{s} d_{i u}^{-k}}
$$

Where, $z_{u}$-unknown value of estimated at $u, z_{i}$-attribute value at control point $i, d_{i u}$-distance between point $i$ and $u$, s-number of control point used in estimation and $k$-a factor.

\section{RESULTS AND DISCUSSION}

\section{Wind Speed Trend and Variation with Height}

Monthly mean wind speeds and directions for the study areas in 2010 and 2018 are given in Table 1 and 2 respectively. The results show that, Accra is having the highest mean wind speed compared to Ho which has the lowest. The results revealed that, the monthly mean wind speed at $10 \mathrm{~m}$ height in Accra showed higher than $7.5 \mathrm{~m} / \mathrm{s}$ for the year 2010. On the other hand, Bolgatanga had the highest mean monthly wind speed at $10 \mathrm{~m}$ in the year 2018 whilst Ketekrachi, Ho and Kumasi had the lowest mean monthly wind speed.

According to the American Wind Energy Association in cooperation with the U.S. Department of Energy and the National Renewable Energy Laboratory, wind speed fluctuates, which has an impact on its potential to generate electricity and operating characteristics. In general, wind speeds are as follows:

$8 \mathrm{kph}(2 \mathrm{~m} / \mathrm{s})$ minimum is required to start rotating most small wind turbines.

$12.6 \mathrm{kph}(3.5 \mathrm{~m} / \mathrm{s})$ is the typical cut-in speed, when a small turbine starts generating power.

$36-54 \mathrm{kph}(10-15 \mathrm{~m} / \mathrm{s})$ produces maximum generation power.

At $90 \mathrm{kph}(25 \mathrm{~m} / \mathrm{s})$ maximum, the turbine is stopped or braked (cut-out speed).

Therefore, all the regions in Ghana except Ketekrachi, Ho and Kumasi have wind energy potential for the year 2010 and 2018 respectively (See Tables 1 and 2). The findings of this study is also consistent with the findings in the literature [36].

Table 1: $\quad$ Monthly mean wind speed and direction at 10m heights for 2010

\begin{tabular}{llllll}
\hline Town & Station ID & Lat & Long & WDx & WDs \\
\hline Wa & 01013WA- & 9.985787 & -1.90992 & 101 & 2 \\
Sunyani & 01032SUN & 7.334941 & -2.3123 & 93 & 5 \\
Bolgatanga & 07000BOL & 10.8 & -0.87 & 48 & 3 \\
Ketekrachi & 07008KRA & 7.801445 & -0.05133 & 69 & 2 \\
Ho & 07017HO- & 6.610149 & 0.478549 & 45 & 1 \\
Kumasi & 17009KSI & 6.6666 & -1.61627 & 109 & 3 \\
Koforidua & 22050KDA & 6.078443 & -0.27139 & 66 & 2 \\
Accra & 23016ACC & 5.603717 & -0.18696 & 154 & 8 \\
Axim & 23001AXM & 4.866509 & -2.24089 & 73 & 3 \\
Salaga & 23022SAL & 8.55 & -0.52 & 88 & 2 \\
\hline
\end{tabular}

*WDx $=$ Wind Direction $(\mathrm{kts}), \mathrm{WDs}=$ Wind Speed $(\mathrm{m} / \mathrm{s})$ 
Table 2: $\quad$ Monthly mean wind speed and direction at 10m heights for 2018

\begin{tabular}{llllll}
\hline Town & Station_ID & Lat & Long & WDx & WDs \\
\hline Wa & 01013WA- & 9.985787 & -1.90992 & 76 & 6 \\
Sunyani & 01032SUN & 7.334941 & -2.3123 & 45 & 3 \\
Bolgatanga & 07000BOL & 10.8 & -0.87 & 63 & 9 \\
Ketekrachi & 07008KRA & 7.801445 & -0.05133 & 160 & 1 \\
Ho & 07017HO- & 6.610149 & 0.478549 & 351 & 1 \\
Kumasi & 17009KSI & 6.6666 & -1.61627 & 26 & 1 \\
Koforidua & 22050KDA & 6.078443 & -0.27139 & 42 & 2 \\
Accra & 23016ACC & 5.603717 & -0.18696 & 204 & 6 \\
Axim & 23001AXM & 4.866509 & -2.24089 & 215 & 6 \\
Salaga & 23022SAL & 8.55 & -0.52 & 86 & 4 \\
\hline WDx & Wind & & & & \\
\hline
\end{tabular}

*WDx $=$ Wind Direction (kts), WDs $=$ Wind Speed $(\mathrm{m} / \mathrm{s})$

\section{Inverse Distance Weighted (IDW) Interpolation of Wind Speed}

Spatial wind mapping provides a visual determination of the potentially high wind resources. In this map, the areas, which have low wind speed or high wind speed, were indicated by the color, green to light pink (Fig. 1), respectively. IDW wind speed map of Ghana shows decreasing by the increase of distance for the selected study stations for the year 2010 and 2018.

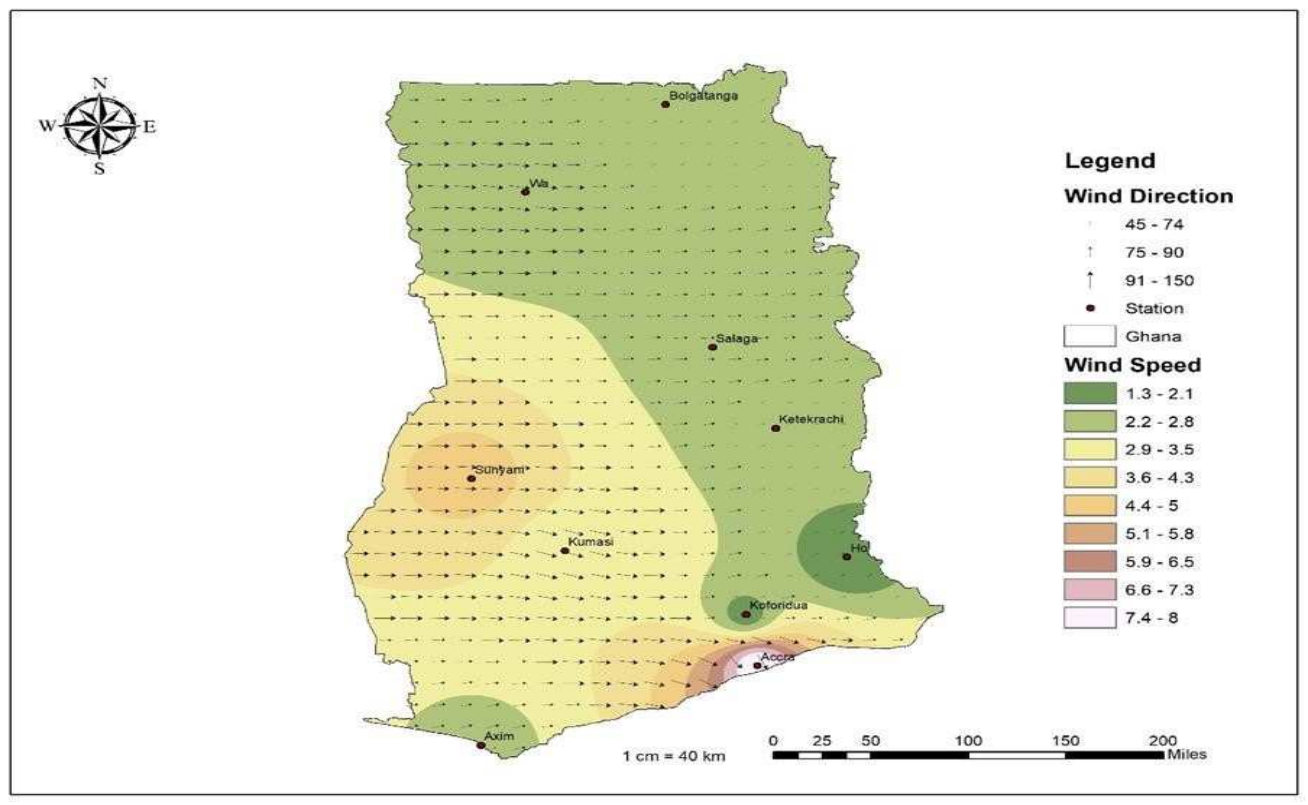

Figure 1: IDW wind potential map for Ghana for the year 2010 Source: Ghana Metrological Service Department 


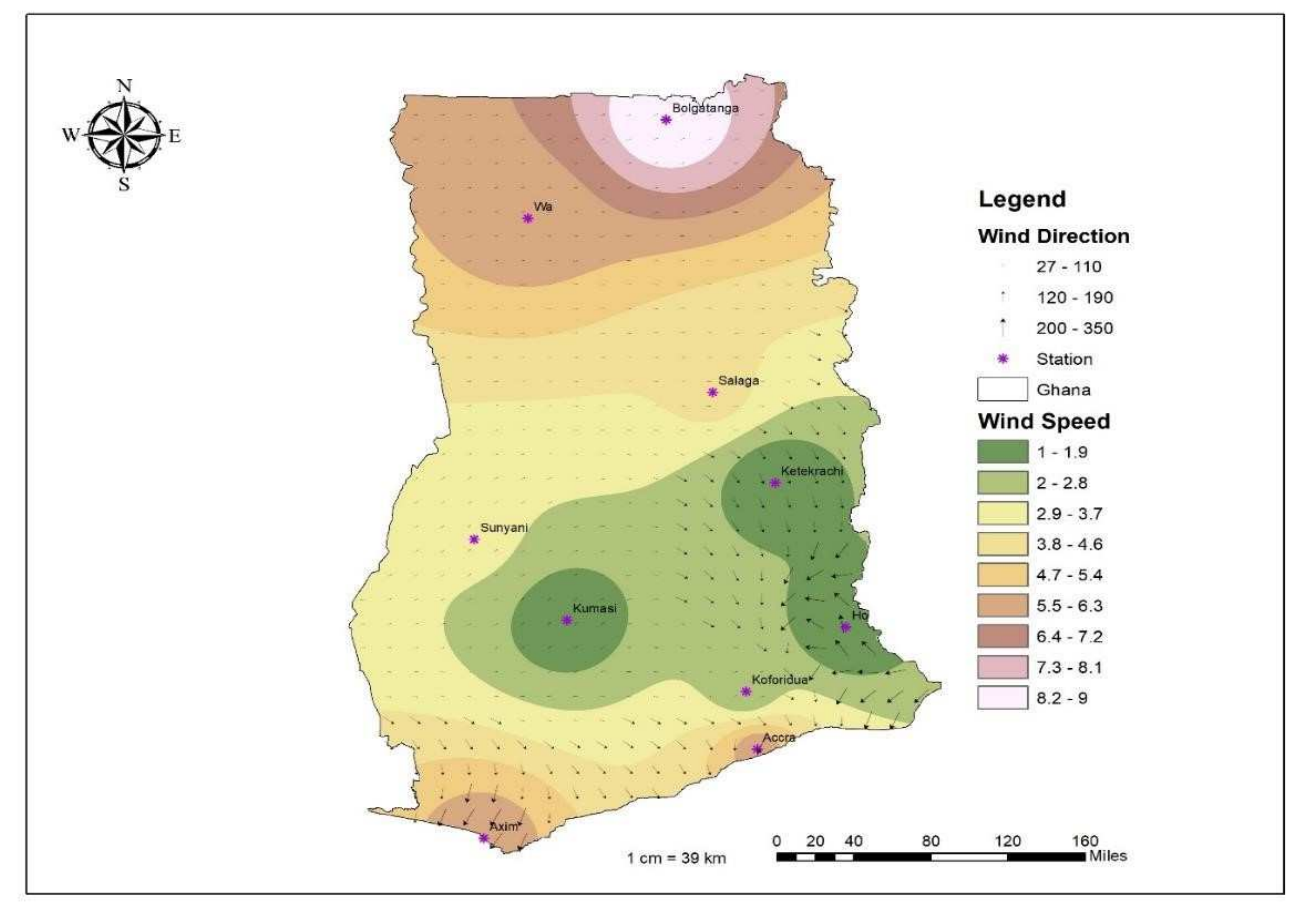

Figure 2: IDW wind potential map for Ghana for the year 2018

Source: Wind finder (https://www.windfinder.com)

Over the year 2010, most of the high wind speeds were in the southern part of Ghana (particularly Greater Accra region and its environs). From table1 and fig. 1 above, it is clear that the highest wind speed for Ghana in 2010 was recorded in the coastal parts of Greater Accra Region of Southern Ghana, with relative speed of $7.4-8 \mathrm{~m} / \mathrm{s}$. This is not, however, the case in 2018 (see table 2 and fig. 2 above) where the highest wind speed of between $8.2-9 \mathrm{~m} / \mathrm{s}$ is recorded in the Upper East Region of Northern Ghana. These results show a drastic change in wind energy potential from 2010 to 2018 for Ghana. Meanwhile, Greater Accra still remains a promising location for wind turbine siting after socio-economic and environmental considerations have been accounted for. The changes that occurred on wind power potential in 2018 (table2, fig.2 above) from 2010, could have resulted from several factors including but not limited to time of year that the data was taken, changes in surface roughness (Diana et. al., 2011), interruption of the trade winds and monsoons which predominates northern and southern Ghana respectively, etc.

\section{Strategy for Enhancing Wind Use and Development in Ghana Country Context}

The Government of Ghana have struggled over the last couple of years to meet electricity demand with supply and various short term and medium-term measures have been put in place by respective governments to address the electricity challenges in Ghana. The challenges are largely attributable to the overdependence on only two energy sources (Hydro - 39.9\% and Thermal Plant - 59.9\%). This situation has called for the need to develop the country's renewable energy sources backed by international organizations. Based on this, [15]; [27], suggest wind energy pursuit is the best option for Ghana to increase its RE energy share mix to $10 \%$ by 2030. One important benefit of embarking on wind energy use in Ghana is that, it will reduce the burden on 
thermal power plants for electricity provision and for that matter exchange rate volatility through oil and gas purchase [37]. This also goes a long way in creating a stable economy for growth. Apart from this, wind energy is clean, renewable, sustainable, and contributes to the reduction in carbon emissions into the atmosphere, thereby keeping global warming and climate change under control. The Government should be interested in developing the wind energy resource through stakeholder participation under various strategies. This section deals with how the wind energy potential identified in Ghana could be developed to enhance the lives of the Ghanaians.

Wind energy is currently the fastest growing renewable energy resource in the world (World Wind Energy Association, 2018) due to the tremendous benefits that accompanies its development. However, Ghana is yet to have its first share of electricity from wind energy sources. Hence, several strategies need to be put in place in ensuring the country is able to harness the wind energy of up to $300 \mathrm{MW}$ [27] to power the agriculture and industry. These measures are explained below.

\section{Stakeholders Involvement in Wind Power Development}

The 2018 wind map on Ghana above shows an improving trend in wind energy potential across the country. Government's involvement of stakeholder participation in the wind energy development is crucial to its success.

First, the government would have to prioritize wind energy production by incentivizing investment into the sector through tax-exempts and regulatory support. In doing this, the Government of Ghana (GoG) would have to engage the services of stakeholders like the Ministry of Energy, Energy Commission, Environmental Protection Agency and the Metrological Service Department for the siting of wind farms at suitable locations to fully harness the wind energy potential of Ghana which is estimated at 300MW [27]. This will be further enhanced through the allocation of funds dedicated for research and development as well as entering into partnership with the likes of China, Germany, Denmark and UK who are the lead players in the industry. Twenty-two wind power stations have been created across Ghana already for measurement of wind speed in order to determine the wind energy potential at those points. Sarpong and Baffoe applied ' GIS for suitable site selection in Ghana and have identified about 142 potential wind sites after taking into consideration environmental factors. This should be further developed with the support of the Environmental Protection Agency, the Energy Commission and the Ministry of Energy. The next few years (2-3 years) should, therefore, be dedicated to locating appropriate sites for wind turbine installations for the production of wind energy in Ghana.

\section{Appropriate use of Electricity Generated from Ghana's Wind Resource}

After all necessary arrangements have been made and turbines installed at suitable sites, the levelized cost of electricity is expected to be relatively cheaper compared to other sources of electricity generation because of very low cost of Operations and Maintenance at the wind farm. For the enclave communities and Ghana at large to fully benefit from the electricity generated, power from around the Upper East Region of Ghana should be channeled to mechanized agriculture to enhance the lives of the majority of people that are farmers in the Northern Part of Ghana. At the same time, the power generated from the south-most part of Ghana (Greater Accra and its environs) should be channeled into augmenting commercial and industrial cost of business. This can ensure enhanced productivity and improved economic growth in the country as there is a strong link 
between access to electricity and GDP growth rate. Moreover, part of the energy that will be generated could be used to extend electricity to the rural folks who are still yet to enjoy electricity through the rural electrification program for both areas where there is wind energy potential. Currently, Ghana has attained $84 \%$ access rate electricity and the government have plans of achieving a $100 \%$ access to electricity in Ghana by 2030 under the guidance of UN. The successful development of the wind energy potentials in Ghana will also ensure this expectation is accomplished.

In Ghana, there is less concern about environment because of our level of development. However, for us to gain the support of international organizations, we must fully take into account the environmental concerns associated with wind power generation and deal with them through technological innovation and by fully involving the Environmental Protection Agency (EPA), other appropriate stakeholders and the International Community.

\section{CONCLUSIONS}

Renewable energy is a hottest topic in the energy fields. Especially renewable resources based on wind. Wind energy is the fastest growing renewable energy resource across the world. Wind data is very essential for wind energy researcher. In Ghana, there is lack of reliable and accurate wind data which is present on spatial representation. Much work has taken place on wind energy potential of Ghana over the years, but Ghana is yet to enjoy any electricity generated from wind. The spatial wind mappings leave a visual determination tool to the decision makers. IDW spatial wind mapping shows the distribution of wind speed in Ghana. With the aid of Geoinformation System, we have been able to establish an improved wind potential of Ghana in Bolgatanga and Accra in 2018 compared to the information in 2010 that showed only Accra and some coastal areas to possess enhanced wind resource for power generation. With a wind speed measure of up to $9 \mathrm{~m} / \mathrm{s}$ at $10 \mathrm{~m}$ height, we recommend that Ghana should focus more attention in developing the wind energy potential in Ghana which could be channeled to Mechanized agriculture in the North and Commercial and Industrial use in the South. This will also be an opportunity for Ghana to ensure 100\% access to electricity in Ghana by 2030.

We advise also that a more thorough survey and analysis of wind speed at the Upper East Region should be carried out for a couple of years at different times and locations to ascertain this change in trend, causes and predictions for the future. This is because, it is possible that the data is biased towards a particular time duration that fits into the movement of the North-East Trade winds and can give a distorted impression of wind energy potential in Ghana.

\section{ACKNOWLEDGEMENT}

We acknowledge the kind contribution of all authors towards the write-up of this manuscript. We also acknowledge the contribution of Dr A. T. Kabo-bah of University of Energy and Natural Resources for direction and guidance during the research as well as all other friends who have contributed in one way or the other in this regard.

\section{REFERENCES}

[1] IEA, International Renewable Energy Agency, United Nations Statistics Division, The World Bank, and World Health Organization, “The Energy Progress Report,” p. 176, 2019. 
[2] IRENA, “Scaling Up Renewable Energy Development in Africa: Impact of IRENA's Engagement," no. January, pp. 1-4, 2019.

[3] Z. Yang, "Using GIS to Determine Wind Energy Potential in Minnesota, USA," Pap. Resour. Anal. Saint Mary's Univ. Minnesota Univ. Cent. Serv. Press. Winona, MN., vol. 15, pp. 1-13, 2013.

[4] D. S. Arndt, M. L. Druckenmiller, and T. Li, "STATE OF THE CLIMATE IN 2018 STATE OF THE CLIMATE IN 2018,” vol. 100, no. 9, 2019.

[5] I. El Kafazi, R. Bannari, and A. Abouabdellah, "Modeling and forecasting energy demand," Proc. 2016 Int. Renew. Sustain. Energy Conf. IRSEC 2016, pp. 746-750, 2016.

[6] C. Cristea and A. F. Jocea, "GIS Application for Wind Energy," Energy Procedia, vol. 85, no. November 2015, pp. 132-140, 2016.

[7] G. Orr, "Global warming [1]," Struct. Eng., vol. 85, no. 17, p. 34, 2007.

[8] M. Asif and T. Muneer, "Energy supply, its demand and security issues for developed and emerging economies," Renew. Sustain. Energy Rev., vol. 11, no. 7, pp. 1388-1413, 2007.

[9] R. Van Haaren and V. Fthenakis, "GIS-based wind farm site selection using spatial multi-criteria analysis (SMCA): Evaluating the case for New York State," Renew. Sustain. Energy Rev., vol. 15, no. 7, pp. 3332-3340, 2011.

[10] Renewable Energy Agency International IRENA, Renewable Energy Market Analysis: GCC 2019. 2019.

[11] T. V. Ramachandra and B. V. Shruthi, "Wind energy potential mapping in Karnataka, India, using GIS," Energy Convers. Manag., vol. 46, no. 9-10, pp. 1561-1578, 2005.

[12] Braun T. "Understanding Energy and Energy Policy" p. 368, 1390.

[13] D. Meimorec, S. Knežević, V. Vorkapić, and D. Škrlec, "Wind energy and environmental protection: Using GIS to evaluate the compatibility of Croatian strategies," 2011 8th Int. Conf. Eur. Energy Mark. EEM 11, pp. 764-772, 2011.

[14] A. Rodrigues, V. Silva, E. Barcelos, C. Silva, and T. Dentinho, "Geographical information systems and cost benefit analysis-based approach for wind power feasibility: A case study of Terceira Island," $J$. Renew. Sustain. Energy, vol. 7, no. 5, 2015.

[15] P. E. Baffoe and D. Sarpong, "Selecting Suitable Sites for Wind Energy Development in Ghana," Ghana Min. J., vol. 16, no. 1, p. 8, 2016.

[16] UNDP, Energy Commision, and Ministry of Foreign Affairs of Denmark, "Renewable Energy Masterplan for Ghana - Work in Progress," 2016.

[17] Energy Commission-Ghana, "Strategic National Energy Plan 2006-2020," vol. 1, pp. 1689-1699, 2006.

[18] G. E. Glass, J. L. Aron, J. H. Ellis, and S. S. Yoon, "Applications of GIS technology to disease control," Pap. Popul. WP 93-05, pp. vi, 39 p., 1993.

[19] A. P. G. Hunter and A. P. I. Bishop, "Introduction to GIS Definition of GIS," Introd. to GIS, pp. 1-13, 2001.

[20] L. Ayalew and H. Yamagishi, "The application of GIS-based logistic regression for landslide susceptibility mapping in the Kakuda-Yahiko Mountains, Central Japan," Geomorphology, vol. 65, no. 1-2, pp. 15-31, 2005.

[21] J. Donohue, "Using GIS to determine the location of onshore and offshore wind farms," 2009.

[22] N. Y. Aydin, E. Kentel, and S. Duzgun, "GIS-based environmental assessment of wind energy systems for spatial planning: A case study from Western Turkey," Renew. Sustain. Energy Rev., vol. 14, no. 1, pp. 364-373, 2010.

[23] D. G. Vagiona and M. Kamilakis, "Sustainable site selection for offshore wind farms in the South Aegean-Greece," Sustain., vol. 10, no. 3, 2018.

[24] M. A. Baseer, S. Rehman, J. P. Meyer, and M. M. Alam, "GIS-based site suitability analysis for wind farm development in Saudi Arabia," Energy, vol. 141, no. October, pp. 1166-1176, 2017. 
[25] B. Sliz-Szkliniarz and J. Vogt, "GIS-based approach for the evaluation of wind energy potential: A case study for the Kujawsko-Pomorskie Voivodeship,” Renew. Sustain. Energy Rev., vol. 15, no. 3, pp. 16961707, 2011.

[26] A. Almoataz Y., M. Said F., and M. Amany B., "Geographic Information Systems (GIS) Application in Wind Farm Planning," Online J. Power Energy Eng., vol. 3, no. 2, pp. 279-283, 2009.

[27] E. Essandoh, E. Osei, and F. Adam, "Prospects of wind power generation in Ghana," Int. J. Mech. Eng. Technol., vol. 2, no. 10, pp. 156-179, 2014.

[28] GRIDCo, "2019 Electricity supply plan for Ghana," pp. 1-87, 2019.

[29] S. Gyamfi, M. Modjinou, and S. Djordjevic, "Improving electricity supply security in Ghana - The potential of renewable energy," Renew. Sustain. Energy Rev., vol. 43, pp. 1035-1045, 2015.

[30] E. N. Kumi, "The Electricity Situation in Ghana: Challenges and Opportunities," CGD Policy Pap., no. September, p. 30, 2017.

[31] United States Agency for International Development, "Integrated Power System Master Plan for Ghana," no. December, pp. 1-285, 2018.

[32] K. H. Yong, M. Z. Ibrahim, M. Ismail, A. Albani, and A. M. Muzathik, "EO15 Wind Mapping in Malaysia Using Inverse Distance Weighted Method," no. June, pp. 60-67, 2011.

[33] J. E. Sanow, S. R. Fassnacht, D. J. Kamin, G. A. Sexstone, W. L. Bauerle, and I. Oprea, "Geometric versus anemometric surface roughness for a shallow accumulating snowpack," Geosci., vol. 8, no. 12, pp. 1-10, 2018.

[34] Q. Wang, M. M. M'Ikiugu, and I. Kinoshita, "A GIS-based approach in support of spatial planning for renewable energy: A case study of Fukushima, Japan,” Sustain., vol. 6, no. 4, pp. 2087-2117, 2014.

[35] C. Zhang and D. McGrath, "Geostatistical and GIS analyses on soil organic carbon concentrations in grassland of southeastern Ireland from two different periods," Geoderma, vol. 119, no. 3-4, pp. 261275, 2004.

[36] K. H. Yong, M. Z. Ibrahim, M. Ismail, A. Albani, and A. M. Muzathik, "EO15 Wind Mapping in Malaysia Using Inverse Distance Weighted Method," pp. 60-67, 2011.

[37] P. DENIZ, "Oil Prices and Renewable Energy: Oil Dependent Countries," J. Res. Econ., vol. 3, no. 2, pp. 139-150, 2019.

[38] Dataset: WindFinder (Nov. 2018) Windspeed Map of Ghana for Nov. 2018 (figure 2) available on Windfinder (https://www.windfinder.com/wind/windspeed.htm)

[39] Dataset: Ghana Meteorological Agency (2010) Windspeed map of Ghana for 2010 (figure 1) available on request at the Agency office in Accra 